\title{
Em direção a um modelo consolidado para a transferência de conhecimentos entre projetos de desenvolvimento de produtos
}

\author{
Alejandro Germán Frank ${ }^{\mathrm{a} *}$, José Luis Duarte Ribeiro ${ }^{\mathrm{b}}$ \\ a*agerfrank@producao.ufrgs.br, UFRGS, Brasil \\ bribeiro@producao.ufrgs.br, UFRGS, Brasil
}

\begin{abstract}
Resumo
A transferência de conhecimentos (TC) entre projetos de desenvolvimento de produtos é um processo composto por diversas etapas. Na literatura, há vários trabalhos que apresentam essas etapas e observa-se heterogeneidade nas nomenclaturas e na organização das mesmas. Além disso, existem várias linhas de pesquisa que têm estudado a TC com diferentes propostas para a interpretação desse processo. Em razão disso, este artigo apresenta uma comparação de nove modelos de TC apresentados por autores de diferentes linhas de pesquisas que compõem dois enfoques diferentes: a dinâmica e interação de equipes (enfoque emergente) e a gestão e organização do conhecimento (enfoque de engenharia). Como resultado dessas análises comparativas, propõe-se um novo modelo de TC que apresenta uma reorganização das ideias discutidas na literatura e uma integração das diferentes propostas existentes, de maneira a se obter um modelo completo e consistente. 0 trabalho também ressalta as contribuições das diversas linhas de pesquisas da TC e as principais diferenças entre elas.
\end{abstract}

Palavras-chave

Transferência de conhecimentos. Desenvolvimento de produtos. Equipes de projeto. Modelo.

\section{Introdução}

0 conhecimento é considerado um recurso estratégico e deve ser aproveitado, pois pode fornecer vantagem competitiva concreta para as empresas (SCHLEGELMILCH; CHINI, 2003; LIAO; HU, 2007; ARGOTE; INGRAM, 2000). Isso é especialmente importante na área de desenvolvimento de produtos (DP), visto que o DP é por natureza um processo intensivo em criação de novos conhecimentos (RAMESH; TIWANA, 1999). 0 conhecimento criado nos projetos de DP deve ser utilizado nos novos projetos, visando a melhoria do desempenho das equipes no que tange a tempo e qualidade (MARSH; STOCK, 2003). Inclusive, projetos desenvolvidos em paralelos têm o potencial de aproveitarem conhecimentos entre si por meio de um gerenciamento simultâneo e integrado dos projetos (NOBEOKA; CUSUMANO, 1995, 1997). 0 aproveitamento de conhecimentos entre diferentes equipes de projeto de DP denomina-se transferência de conhecimentos (TC) entre projetos.
Na literatura que aborda o tema da TC se observa que a maior parte dos trabalhos preocupa-se com a análise dos fatores que influenciam a TC, sendo esta considerada como se ocorresse em um único momento e não em um processo composto por várias etapas. De acordo com Szulanski (2000), considerar a TC como um processo e analisar a estrutura das etapas faz com que aumente a complexidade do estudo. Contudo, é necessário tratar a TC como um processo, pois os fatores organizacionais analisados na literatura podem ter diferentes graus de impacto em cada uma das etapas da TC. Por outro lado, existem alguns trabalhos que se preocuparam com o estudo do processo de TC e suas etapas (por exemplo: ZOLLO; WINTER, 2002; SZULANSKI, 2000; ALAVI; LEIDNER, 2001; MAJOR; CODEY-HAYES, 2000). Porém, observa-se muita heterogeneidade em termos de nomenclatura e etapas propostas para explicar tal processo. Assim sendo, apesar do processo de TC ser 
um tema discutido por alguns autores desde a década de 1990, observa-se uma falta de homogeneização das propostas existentes na procura de um modelo consolidado.

Considerando o exposto acima, o presente trabalho tem por objetivo apresentar uma análise comparativa dos modelos de TC existentes na literatura, com vista a propor um modelo de TC que integre as diferentes ideias e abordagens existentes. 0 artigo apresenta uma análise de nove modelos de TC, abordando propostas da linha das ciências sociais (abordagem emergente), como também da linha da gestão tecnológica e dos sistemas de informação (abordagem de engenharia).

\section{Transferência de conhecimentos entre projetos de desenvolvimento de produto}

A TC entre equipes de projeto é um processo que envolve o movimento do conhecimento desde uma fonte para um receptor e a subsequente absorção e utilização desse conhecimento, tendo como finalidade melhorar a capacidade para capitalizar experiências passadas e executar atividades (CUMMINGS; TENG, 2003; DAVENPORT; PRUSAK, 1998; SZULANSKI, 2000; HSU, 2008). Além de trabalhos que abordam explicitamente o conceito de TC, na literatura há estudos que utilizam outras terminologias para a TC (ANTONI et al., 2005; VAN WIJK; JANSEN; LYLES, 2008). Por exemplo, a TC tem sido designada pelos termos: aprendizagem interprojetos (PRENCIPE; TELL, 2001; KONERS; GOFFIN, 2007a); compartilhamento de conhecimentos (CUMMINGS, 2004; RAUNIAR et al., 2008); fluxo de conhecimento da organização (GUPTA; GOVINDARAJAN, 2000); reutilização do conhecimento entre projetos (MARKUS, 2001; SMALLENBURG; HALMAN; VAN MAL, 1996); melhora contínua e aprendizagem entre projetos (NILSSON-WITELL; ANTONI; DAHLGAARD, 2005; BARTEZZAGHI; CORSO; VERGANTI, 1997); inovação contínua em projetos de produto (BOER et al., 2001), entre outros. Cada um desses conceitos observa a TC de uma perspectiva diferente, existindo complementação entre eles. Por exemplo, autores que discutem a TC como disseminação ou compartilhamento preocupam-se prioritariamente com a fonte ou produtor do conhecimento; outros que se interessam pelo receptor estudam a TC desde a perspectiva da captura e absorção do conhecimento. Contudo, ambas as perspectivas compõem um processo mais abrangente denominado aqui como TC. No presente trabalho prefere-se usar essa nomenclatura pelo fato dela ter sido utilizada em pesquisas que seguem uma abordagem mais prática, focalizada na solução de problemas, como é o caso da presente pesquisa.
Embora a TC seja considerada um processo composto por várias etapas (SZULANSK1, 2000), algumas pesquisas a tratam como um evento único, sem entrar na análise de como esta acontece (por exemplo: CUMMINGS; TENG, 2003; DU, 2007; VAN DEN HOOFF; HUYSMAN, 2009). Geralmente esses trabalhos preocupam-se com os fatores que influenciam a TC. Já outros autores enfatizam a importância de desdobrar a TC em etapas (SZULANSKI, 2000; SCHLEGELMILCH; CHINl, 2003). Autores que abordam a TC como um processo têm apresentado diferentes modelos que buscam explicar a sequência de etapas que o conhecimento percorre desde a fonte até chegar e ser utilizado pelo receptor. No presente trabalho serão analisados esses modelos para realizar uma comparação entre os mesmos e avançar em direção a um modelo consolidado que integre as diferentes visões. Para tanto, a seguir são apresentados o método de pesquisa utilizado e, posteriormente, os resultados da análise.

\section{Procedimentos para a análise dos modelos de TC}

Para a construção das etapas do processo de TC, foram identificados nove modelos de TC descritos na literatura. Esses modelos foram escolhidos por apresentarem uma síntese da visão de cada área de pesquisa que estuda a TC.

Os modelos foram organizados em duas grandes linhas de pesquisa, conforme o estudo realizado por Van Den Hooff e Huysman (2009): o enfoque emergente, composto por autores das ciências sociais; e o enfoque da engenharia, composto por autores vinculados à gestão tecnológica e aos sistemas de informação. Essas duas classificações referem-se ao propósito dos trabalhos dos autores estudados. 0 enfoque emergente centra-se no estudo da dinâmica entre as equipes e a interação pessoal (VAN DEN HOOFF; HUYSMAN, 2009). Dentro do enfoque emergente foram identificados modelos que enfatizam as seguintes teorias e enfoques: (i) evolução das organizações; (ii) comportamento das organizações; e (iii) criação do conhecimento nas organizações. Por outro lado, o enfoque de engenharia centra-se no gerenciamento e no controle organizacional para o aproveitamento do conhecimento (VAN DEN HOOFF; HUYSMAN, 2009). Dentro desse enfoque foram identificados modelos baseados nas seguintes teorias e abordagens: (i) processamento da informação; (ii) criação de memória organizacional; (iii) comunicação e tradução do conhecimento; (iv) melhoria contínua e aprendizagem entre projetos. Por conseguinte, observa-se que, na consideração desses modelos, pode-se ter uma visão bastante ampla sobre a TC desde diferentes perspectivas. 
Os modelos foram comparados, etapa por etapa, para identificar semelhanças e diferenças. A análise realizada neste trabalho considera, quando possivel, as descrições de cada etapa, as escolhas semânticas dos diferentes modelos e a ordem sequencial apresentada por cada autor.

A comparação dos modelos permitiu organizar as etapas da TC por semelhança em termos de semântica e conteúdo. Isso foi feito considerando a descrição fornecida por cada autor. Para extrair as fases e etapas da TC, foi realizada uma análise de conteúdo dos modelos analisados, de acordo com a abordagem proposta por Bardin (1977). Seguindo essa abordagem, foram utilizadas duas regras de codificação das etapas propostas pelos autores dos modelos. Essas duas regras de codificação consistem em: (i) regra de recorte, na qual se escolhe a unidade de análise; e (ii) regra de categorização, que define a forma de construção do agrupamento dos dados (construção das fases). Como regra de recorte foi priorizada a análise temática, na qual o agrupamento das etapas de TC propostas pelos autores é realizado por unidades de significados comuns no conteúdo analisado. Como regra de categorização, que conduz à definição da nomenclatura de cada fase, foi empregado o procedimento denominado por milha, que define o título conceitual de cada categoria no final da operação, uma vez agrupados os elementos similares. Nessa categorização, também se utilizou o critério semântico que define as categorias por temas comuns aos elementos agrupados.

Através da análise de conteúdo, foram identificadas cinco fases principais que compõem a TC: (i) fase 0 - produção do conhecimento na fonte; (ii) fase 1 - identificação do conhecimento; (iii) fase 2 - processamento do conhecimento; (iv) fase 3 - disseminação do conhecimento; e (v) fase 4 - aplicação do conhecimento no receptor. Essas fases aparecem detalhadas no Quadro $1 \mathrm{e}$ serviram de base para posicionar as etapas de TC propostas pelos diferentes autores.

Após a comparação dos modelos, foi possível consolidar as informações em uma estrutura geral, que contempla a maior parte das proposições encontradas na literatura. Para tanto, foram definidas as etapas constituintes de cada fase da TC. Feita essa definição, as fases, etapas e descrição do respectivo escopo foram sintetizadas no Quadro 1. Abordagens e teorias subjacentes aos modelos de TC

O Quadro 1 apresenta uma síntese de nove modelos que descrevem as etapas do processo de TC. Algumas discussões iniciais sobre as etapas da TC foram realizadas por Cohen e Levintal (1990), Trott, Cordey-Hayes e Seaton (1995) e Horton (1999). Essas ideias sobre a modelagem da TC foram analisadas e sintetizadas por Major e Cordey-Hayes (2000), que apresentaram um modelo composto por cinco etapas. 0 modelo proposto por esses autores segue uma abordagem baseada na teoria do processamento de informações, que tem sido usada para estudos sobre aprendizagem e criação de memórias nas equipes de DP (AKGÜIN; LYNN; YILMAZ, 2006). Também Markus (2001) apresentou um modelo muito similar ao de Major e Cordey-Hayes (2000), mas com algumas variações na nomenclatura das fases propostas.

Posteriormente, Liyanage et al. (2009) integraram ao modelo de TC proposto por Major e Cordey-Hayes (2000) a concepção da teoria da criação do conhecimento desenvolvida por Nonaka (1994). Porém, diferenciando-se dos autores anteriores, Liyanage et al. (2009) baseiam seu modelo na teoria da comunicação e tradução, que considera elementos tais como a fonte e o receptor do conhecimento, o tipo de canal de comunicação utilizado e a mensagem de comunicação, entre outros aspectos também discutidos por autores como Gupta e Govindarajan (2000) e Szulanski (2000). Também Alavi e Leidner (2001) consideram a criação do conhecimento como a base para a TC. 0 modelo apresentado por esses autores é baseado nas teorias da sociologia do conhecimento e na visão das organizações como coletivos sociais e sistemas de conhecimento. Esses autores consideram as organizações como entidades compostas por um conjunto de "processos de conhecimentos", que envolvem etapas similares às utilizadas em outros modelos para explicar a TC. Alavi e Leidner (2001) descrevem esse processo a partir da perspectiva da criação de memórias entre os grupos que transferem conhecimentos, o que está baseado na teoria da memória organizacional, utilizada também por autores como Lewis, Lange e Gillis (2005), Nevo e Wand (2005) e Argote e Ingram (2000). Nesse enfoque, analisam-se as memórias coletivas que se criam entre os indivíduos e que servem para a disseminação do conhecimento.

Uma segunda abordagem para a modelagem da TC foi proposta por Bartezzaghi, Corso e Verganti (1997) e Boer et al. (2001). As etapas propostas por esses autores apresentam características muito semelhantes aos autores citados acima, todos eles apoiados em linha de pesquisa de áreas relacionadas à gestão tecnológica (abordagem de engenharia). Destaca-se junto a esses autores a ênfase que eles atribuem para o aprendizado que ocorre no processo de TC, visando a melhoria contínua dos projetos de DP. Contudo, enquanto Bartezzaghi, Corso e Verganti (1997) discutem em profundidade os aspectos do processo de TC, Boer et al. (2001) apenas tangenciam esse assunto. De qualquer forma, as etapas e nomenclaturas usadas no trabalho de Boer et al. (2001) foram utilizadas para reforçar as comparações dentro dessa linha de pesquisa. 


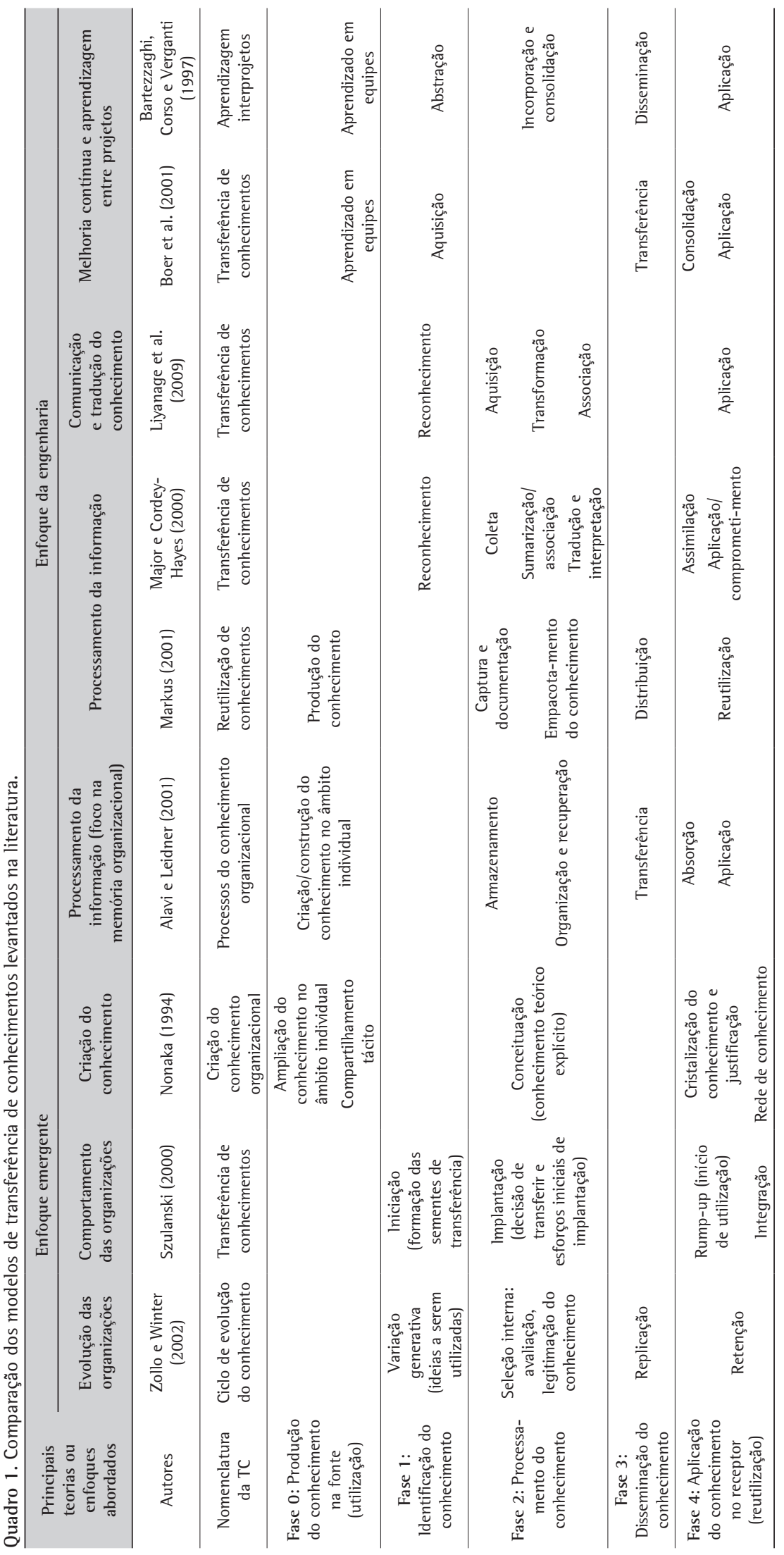


Uma terceira abordagem para a modelagem da TC é proposta por autores das ciências sociais (abordagem emergente), tais como Zollo e Winter (2002), Szulanski (2000) e Nonaka (1994). Esse grupo de autores propõe modelos para a TC priorizando os aspectos comportamentais do processo. No modelo de Zollo e Winter (2002), há uma sequência de etapas baseada na teoria evolucionária das organizações. A ideia desses autores é utilizar modelos de comportamento da biologia e adaptá-los ao comportamento organizacional, sendo a organização considerada como um mecanismo vivo que evolui no tempo. Anteriormente, Kogut e Zander (1992) e Zander e Kogut (1995) trabalharam sob esta perspectiva para representar o conhecimento organizacional. Um segundo modelo da abordagem emergente apresentado é o de Szulanski (2000), que discute a TC desde a visão do comportamento das pessoas que compartilham (ou não) com outras equipes o conhecimento que possuem. 0 modelo de Szulanski (2000) descreve as etapas da implantação do conhecimento transferido para um novo contexto.

Por outro lado, um terceiro modelo é apresentado por Nonaka (1994). Esse modelo difere dos demais, pois é fortemente orientado à interação pessoal das diferentes equipes. Além disso, o trabalho de Nonaka (1994) propõe a teoria da criação de conhecimento nas organizações e aplica esses conceitos no desenvolvimento das etapas da TC entre equipes de trabalho em um ambiente colaborativo. 0 modelo de Nonaka (1994) desdobra com maior detalhamento que os demais as últimas etapas da TC, quando o conhecimento é assimilado em outras equipes e gera novos conhecimentos para as equipes.

\section{Análise das etapas da TC propostas nos diferentes modelos}

As etapas propostas por cada modelo foram agrupadas em fases principais da TC e em etapas que compõem cada fase, conforme apresentado no Quadro 1. Na comparação entre os modelos observam-se diferenças substanciais na terminologia e no desdobramento das etapas que compõem o processo de TC. Os espaços em branco entre fases representam aspectos não discutidos pelos autores. As maiores diferenças referem-se a questões semânticas e ao detalhamento das etapas, sendo possível identificar uma estrutura comum às etapas de TC propostas. Dessa maneira, o agrupamento e a comparação dos modelos auxiliam a identificar características que definem as fases principais do processo de TC. Essas fases são descritas a seguir.

\subsection{Fase 0: Produção do conhecimento na fonte}

Essa fase é denominada como fase 0 por acontecer antes do conhecimento ser transferido, não fazendo parte do processo de transferência propriamente dito. Antes de começar o processo de TC, há uma produção do conhecimento na fonte. Isto ocorre tipicamente no âmbito de indivíduos ou equipe de um único projeto, como descreve Markus (2001). Essa fase pode ser desdobrada em etapas, tais como: criação do conhecimento no âmbito de cada indivíduo, ampliação do conhecimento no âmbito individual e compartilhamento tácito de conhecimentos entre os indivíduos durante as rotinas de trabalho (NONAKA, 1994; ALAVI; LEIDNER, 2001).

Nessa fase, a equipe trabalha nas atividades do desenvolvimento do projeto e cria novos conceitos e ideias para inovar nos produtos que desenvolve. $\mathrm{Na}$ fonte acontece um processo de aprendizado e TC interna entre as fases de um único projeto, já que a equipe amadurece as ideias sobre o projeto à medida que o mesmo avança no desenvolvimento e transfere o que aprendeu para as etapas seguintes (BARTEZZAGHI; CORSO; VERGANTI, 1997; BOER et al., 2001). Assim sendo, existe um processo de conversão de conhecimento (NONAKA, 1994), no qual os integrantes das equipes aprendem fazendo o trabalho através do compartilhamento de conhecimento tácito. Além disso, o conhecimento é explicitado em documentos, tais como relatórios e manuais. Até aqui, o conhecimento explicitado é parte da fonte e está associado apenas ao contexto onde a fonte o produziu. Como resultado, a equipe de projeto começa a desenvolver suas próprias rotinas de trabalho com o know-how de como lidar na resolução dos seus problemas de projeto (ZOLLO; WINTER, 2002; COHEN; BACDAYAN, 1994).

\subsection{Fase 1: Identificação do conhecimento}

A fase aqui denominada de identificação do conhecimento contempla a capacidade de localizar o conhecimento útil de um projeto para ser disseminado, e a estruturação do mesmo para esse fim. Desde o ponto de vista da teoria evolucionária do conhecimento, essa fase pode ser definida como a variação generativa, na qual surgem ideias de projetos passados que podem ser aproveitadas em novos projetos através da recombinação delas (ZOLLO; WINTER, 2002). Szulanski (2000) denomina essa etapa de "iniciação das sementes”, pois as ideias identificadas são as sementes iniciais para o processo de TC.

Essa fase pode ser desdobrada em várias etapas, de acordo com as diferentes propostas dos autores analisados no Quadro 1. Em primeiro lugar, as sementes 
de conhecimentos originadas em outros projetos precisam ser reconhecidas, como destacam os modelos de Major e Cordey-Hayes (2000) e Liyanage et al. (2009). Nesse sentido, a própria fonte precisa perceber o valor de um determinado conhecimento e identificar nele uma oportunidade de transferência, além de ser necessária a predisposição da fonte para disponibilizá-lo a potenciais receptores (SZULANSKI, 2000; GUPTA; GOVINDARAJAN, 2000). Em alguns casos, o próprio receptor pode ser quem identifica na fonte um conhecimento útil para ser reutilizado. Isso acontece em situações onde existem relacionamentos mais próximos entre equipes de diferentes projetos, através de atividades em comum, como participação conjunta em algumas tarefas, diálogo e discussão dos resultados obtidos nos diferentes projetos ou equipes cruzadas nas quais existem alguns agentes intermediários entre as diferentes equipes (KONERS; GOFFIN, 2007a, b).

Uma vez identificado o conhecimento a ser transferido, este passa por um processo de abstração e generalização (BARTEZZAGHI; CORSO; VERGANTI, 1997). 0 conhecimento primeiro deve ser abstraído do contexto específico no qual se encontrava quando foi identificado e, após, deve ser generalizado em um conceito teórico, possível de ser aplicado em outros contextos. Nonaka (1994) denomina isso como conceituação, já que se criam conhecimentos conceituais e genéricos sobre os processos. Alguns exemplos poderiam ser: padrões de comportamento dos materiais do produto, formas de lidar com alguns tipos de fornecedores, métodos para resolver determinados problemas. 0 processo de abstração e generalização é considerado neste trabalho como a parte inicial de outras etapas mais abrangentes descritas nos modelos, tais como: aquisição (BOER et al., 2001; LIYANAGE et al., 2009), coleta (MAJOR; CODEY-HAYES, 2000) ou captura do conhecimento (MARKUS, 2001), as quais abrangem também parte da fase seguinte que será discutida. Ainda, deve-se levar em consideração que os conhecimentos originários de cada fonte têm diferentes graus de abstração e generalização, sendo mais fáceis de transferir aqueles conhecimentos que possuem uma teoria clara que os sustente (KOGUT; ZANDER, 1992).

\subsection{Fase 2: Processamento do conhecimento}

Nessa segunda fase são realizados os esforços iniciais para transferir o conhecimento identificado na fonte (SZULANSK1, 2000). 0 conhecimento abstraído precisa ser processado e incorporado a meios formais de disseminação do conhecimento que sejam úteis para outras equipes. Por essa razão, essa fase trabalha fortemente com conhecimento explícito, principalmente nas dimensões de externalização e combinação do conhecimento (NONAKA, 1994). De acordo com os elementos da TC propostos por Szulanski (2000), essa fase processa e constrói a mensagem que será transmitida aos receptores.

Os autores destacados no Quadro 1 apresentam diferentes perspectivas do que acontece no que é denominado aqui como processamento do conhecimento. Por exemplo, Zollo e Winter (2002), baseados na teoria evolucionária das organizações, consideram que essa é uma fase de seleção interna, na qual o conhecimento identificado é avaliado e legitimado para sua posterior disseminação. Conforme esses autores, nesta etapa sintetiza-se o que será útil para outros projetos. Uma vez avaliado aquilo que realmente é pertinente para outros projetos, o conhecimento é incorporado ou documentado em formatos explícitos e genéricos, úteis para toda a organização, tais como manuais de melhores práticas, lições aprendidas ou processos de negócios (BARTEZZAGHI; CORSO; VERGANTI, 1997; MARKUS, 2001). Dessa maneira, o conhecimento da equipe fica disponível, ou armazenado, conforme designado por Alavi e Leidner (2001), em um formato explícito de caráter geral. Porém, geralmente as primeiras ideias escritas precisam ainda ser melhoradas e, portanto, é necessário realizar uma reestruturação dos conceitos explicitados, trabalhando a dimensão da combinação do conhecimento (NONAKA, 1994). Alavi e Leidner (2001) definem isso como organização e recuperação do conhecimento armazenado. Por outro lado, Markus (2001) define essas atividades como "empacotamento do conhecimento", pois o conhecimento está sendo preparado como um pacote de produto para ser enviado aos receptores. Para tanto, desdobrando as atividades, em primeiro lugar realiza-se uma redução dos conceitos, quando estes ficaram excessivamente abrangentes ou genéricos, ou quando contêm informação desnecessária para outros projetos. Essa organização é denominada como sumarização (MAJOR; CORDEY-HAYES, 2000) ou transformação do conhecimento (LIYANAGE et al., 2009). Posteriormente, uma segunda etapa consiste em reinterpretar os conceitos e associá-los com outras informações, de maneira que estes fiquem consolidados. Isso é denominado como associação de conhecimentos (LIYANAGE et al., 2009) ou tradução e interpretação do conhecimento (MAJOR; CORDEY-HAYES, 2000). Observando essa fase da TC desde a perspectiva da teoria do processamento da informação, pode ser considerada como resultado final a criação de uma memória semântica (conhecimento explícito e articulado em documentos) e episódica (conhecimento específico do contexto e de situações) do grupo, a 
qual será utilizada posteriormente na disseminação do conhecimento para as outras equipes (ALAVI; LEIDNER, 2001).

Quando a TC é realizada por meios informais, tais como interação das equipes em reuniões e atividades compartilhadas, rotatividade de integrantes ou ambientes compartilhados, há forte ênfase na socialização do conhecimento (transferência de conhecimento tácito). Assim sendo, a fase aqui nomeada como processamento do conhecimento não é clara e definida como foi descrito acima. Nesse caso, etapas como a avaliação e legitimação do conhecimento, a sumarização e o acondicionamento do mesmo acontecem na mente das pessoas que estão trocando ideias sobre os diferentes projetos. Por essa razão, no Quadro 1, observa-se que o modelo de Nonaka (1994), que enfatiza a interação entre pessoas, apresenta lacunas e pouco detalhamento nessa fase. Para Nonaka (1994), o processamento acontece já na conceituação, pois esse autor considera que o conceito está sendo criado na discussão entre integrantes de diferentes equipes e não apenas de uma única equipe. Por conseguinte, estabelece-se que o processamento pode seguir duas rotas: uma formal, criando uma memória semântica, explícita, à qual outras equipes poderão acessar posteriormente e outra informal, criando uma memória episódica, implícita, já compartilhada entre as equipes através de algumas pessoas intermediárias.

\subsection{Fase 3: Disseminação do conhecimento}

A terceira fase do processo de TC é a disseminação do conhecimento, que consiste em colocar à disposição dos potenciais receptores o conhecimento que já foi processado na fonte. Para tanto, nessa fase são definidas as rotas e direções que terá a TC assim como o nível de disseminação entre as equipes de projetos (BOER et al., 2001). Alguns autores denominam essa atividade como disseminação (BARTEZZAGHI; CORSO; VERGANTI, 1997), transferência (BOER et al., 2001) ou distribuição do conhecimento (MARKUS, 2001).

0 elemento da TC predominante nessa fase é o canal que será utilizado para disseminar o conhecimento (SZULANSKI, 2000). Os canais para a disseminação podem ser meios físicos, como bibliotecas com manuais e documentos (ZOLLO; WINTER, 2002; PRENCIPE; TELL, 2001; LYNN; REILLY; AKGÜN, 2000), ou tecnologias da informação, como portais, websites, sistemas de gestão do conhecimento (LIU; KE, 2007; LYNN; REILLY; AKGÜN, 2000; TSENG, 2008). Através desses meios o conhecimento explicitado e processado é disponibilizado para o acesso fácil de outras equipes.
Por outro lado, uma situação diferente acontece quando há uma disseminação de conhecimentos tácitos. Nesse caso, as próprias pessoas podem ser o canal de disseminação, compartilhando o que elas sabem através de palestras ou reuniões entre diferentes equipes de projeto ou no trabalho colaborativo entre equipes (KONERS; GOFFIN, 2007a; NONAKA, 1994). Nesse caso, a disseminação passa a ser também um compartilhamento de conhecimento, pois não há um repositório intermediário onde o conhecimento fica armazenado até alguém o procurar e utilizar, mas acontece um processo ativo entre a fonte e o receptor que trocam ideias e aprendem compartilhando o que sabem.

Observa-se assim que há uma diferença entre as linhas de pesquisa em relação a essa fase. Zollo e Winter (2002), Szulanski (2000) e Nonaka (1994) são autores que estudam a TC desde uma perspectiva emergente, enfatizando a interação das pessoas. Consequentemente, esses autores não detalham essa fase, pois a mesma é considerada junto com o processamento do conhecimento, considerando que as equipes estão construindo conjuntamente o conhecimento organizacional, embora posteriormente o mesmo possa ser documentado. Já na linha de autores como Alavi e Leidner (2001), Boer et al. (2001), Bartezzaghi, Corso e Verganti (1997) e Markus (2001), cada grupo cria seu conhecimento e o disponibiliza, como se fossem equipes isoladas. Portanto, esses autores detalham melhor essa fase, principalmente enfatizando a utilização de canais formais de TC.

\subsection{Fase 4: Aplicação do conhecimento na fonte (reutilização)}

A última fase consiste na reutilização do conhecimento em outro contexto daquele no qual tinha sido criado (SZULANSKl, 2000). Aqui, a disposição do receptor e a capacidade absortiva do mesmo para reutilizar os conhecimentos são elementos-chave do processo de TC (COHEN; LEVINTAL, 1990; GUPTA; GOVINDARAJAN, 2000).

$\mathrm{Na}$ primeira etapa dessa fase, o conhecimento genérico que foi disseminado precisa ser absorvido, assimilado e consolidado pela equipe do novo projeto (ALAVI; LEIDNER, 2001; MAJOR; CODEY-HAYES, 2000; BOER et al., 2001). Os integrantes do novo projeto se interessam por uma solução genérica de outro projeto, que foi disseminada, e a estudam para entender e aprender sobre ela, visando sua possivel aplicação no novo contexto. A equipe estuda como aplicar a solução e quais as adaptações necessárias, consolidando dessa maneira o conhecimento, ainda conceitual, para o novo projeto. 
A seguir, os conceitos assimilados pela equipe do novo projeto são colocados em prática no novo projeto até se obter uma solução satisfatória. Essa etapa é definida por Szulanski (2000) como rump-up. No rump-up, o conhecimento é cristalizado na equipe do novo projeto, através do teste, na prática, da realidade e aplicabilidade dos conceitos disseminados por outras equipes (NONAKA, 1994). Os testes e a aplicação do conhecimento no novo contexto levarão a uma avaliação do grau de aplicabilidade e da qualidade do mesmo em outros contextos, processo definido por Nonaka (1994) como justificação do conhecimento. Outros autores definem essa etapa como: aplicação do conhecimento (ALAVl; LEIDNER, 2001; BOER et al., 2001; BARTEZZAGHI; CORSO; VERGANTI, 1997; LIYANAGE et al., 2009; MAJOR; CODEY-HAYES, 2000) e reutilização do conhecimento (MARKUS, 2001), considerando que as mesmas envolvem os aspectos citados acima.

Por outro lado, uma diferença um pouco maior nas etapas desta fase é observada no modelo de Zollo e Winter (2002). Esses autores consideram uma única etapa, denominada replicação, a qual envolve a disseminação do conhecimento (que pertence à fase anterior estabelecida neste trabalho), a absorção pela nova equipe e a aplicação prática no novo contexto. A ideia nesse modelo é que o conhecimento está sendo replicado, fora do contexto original, já desde o momento que ele é compartilhado até a sua aplicação específica no novo projeto. Contudo, as atividades consideradas dentro da etapa de replicação não diferem, em aspectos gerais, dos demais autores.

Alguns autores ainda acrescentam uma última etapa nessa fase, depois do conhecimento ter sido colocado em prática. Szulanski (2000) define uma etapa de integração, onde são obtidos os resultados satisfatórios e o conhecimento de outro projeto passa a ser incorporado, de maneira permanente, na equipe de projeto. No modelo de Zollo e Winter (2002), essa etapa é vista como a retenção do conhecimento, pois o conhecimento agora passa a fazer parte da rotina da equipe que o absorveu, mudando assim a forma de trabalho da mesma. Assim, o conhecimento passa a ser integrado à rede de conhecimentos da nova equipe, como uma apropriação do mesmo, sendo parte da forma de resolução de problemas que a rede de participantes utiliza entre os projetos (NONAKA, 1994).

\section{Proposta de um novo modelo de transferência de conhecimentos entre equipes de projeto de DP}

Esta seção apresenta um modelo para a TC entre equipes de projeto de DP que sintetiza e unifica as ideias dos modelos discutidos na seção anterior, onde explicou-se que a maioria dos modelos discutidos têm características similares ou complementares. Porém, considerando as abordagens propostas por Van Den Hooff e Huysman (2009) para a TC, podem-se identificar duas vertentes principais de autores que tratam sobre modelos de TC já apresentados: os autores do enfoque emergente (por exemplo: NONAKA, 1994; SZULANSKI, 2000; ZOLLO; WINTER, 2002) e os autores do enfoque de engenharia (por exemplo: ALAVI; LEIDNER, 2001; BOER et al., 2001; BARTEZZAGHI; CORSO; VERGANTI, 1997; MARKUS, 2001). A proposta do modelo de TC deste artigo sintetiza as etapas anteriormente discutidas e segue a nomenclatura utilizada pelos autores do enfoque de engenharia (VAN DEN HOOFF; HUYSMAN, 2009). Isso se deve às seguintes razões: o pragmatismo dessa linha de autores para tratar a TC, já que estes se preocupam principalmente com o desenvolvimento de soluções para as equipes de DP; o nível de detalhamento maior das etapas; e a ênfase mais aplicada especificamente ao contexto do DP, que coincide com o objetivo deste artigo. No entanto, as etapas propostas pelos autores do enfoque emergente foram usadas para a melhor compreensão de cada etapa e, também, para acrescentar algumas etapas pouco detalhadas pela outra linha de pesquisa.

0 modelo proposto é apresentado no Quadro 2. 0 mesmo divide-se em fases, as quais por sua vez dividem-se em etapas. Nesse quadro também apresentam-se os autores utilizados para a nomenclatura das etapas e a explicação do que acontece nas mesmas. Conforme se pode observar no modelo proposto, a TC começa, na fase 0 - produção do conhecimento na fonte, que se divide em duas etapas: (i) criação e ampliação do conhecimento no âmbito individual, na mente de cada pessoa; e (ii) utilização e aprendizado dentro de cada equipe. Para o bom desempenho da fase 0 é essencial o desenvolvimento da capacidade de criação de conhecimento nas equipes. Como resultado dessa fase obtêm-se novas rotinas de trabalho e novas soluções para o projeto desenvolvidas por uma equipe específica.

A fase 1 - identificação do conhecimento - é composta por duas etapas: (i) o reconhecimento do conhecimento a ser disponibilizado para outras equipes; e (ii) a abstração e conceituação desse conhecimento. Para o sucesso dessa fase, é necessário desenvolver na equipe a capacidade de identificar conhecimentos úteis e aplicáveis a outros contextos. 0 resultado dessa fase é a criação de conceitos abstratos e genéricos que podem ser aplicáveis para outros usos, em outros projetos.

0 passo seguinte do processo de TC é a fase 2 - processamento do conhecimento. Conforme foi discutido na seção 3 , essa fase é a que apresenta 
maiores diferenças nas nomenclaturas utilizadas (ver também o Quadro 1). Assim sendo, propõem-se três novas nomenclaturas para as etapas, as quais buscam resumir as ideias dos diferentes modelos discutidos: (i) explicitação e incorporação do conhecimento aos registros formais, tais como lições aprendidas, relatórios de projetos etc.; (ii) acondicionamento do conhecimento explicitado com a finalidade de torná-lo claro, entendível e sintetizado para outras equipes; e (iii) consolidação do conhecimento explicitado, através do acréscimo de fontes adicionais que enriqueçam o conteúdo. Nessa fase as equipes precisam possuir capacidade para explicitar os conhecimentos e apresentá-los de maneira clara e resumida. Como resultado, obtêm-se registros formais dos conhecimentos e a criação da memória explícita das equipes.

A fase 3 - disseminação do conhecimento - é composta por uma única etapa, que é a própria disseminação ou distribuição do conhecimento. A diferença com o processo de TC em si é que essa fase considera apenas o ato de disponibilizar o conhecimento, enquanto que a TC é o processo completo, que engloba as várias etapas descritas neste artigo. Outros trabalhos utilizam TC e disseminação como sinônimos. Contudo, nessa fase pretende-se ressaltar a atividade de criar e utilizar canais e meios para que outros possam acessar os conhecimentos. Assim sendo, a principal capacidade necessária nessa fase é a de distribuição, através do desenvolvimento e utilização de canais de disseminação ou distribuição. 0 resultado dessa fase é a acessibilidade ao conhecimento do projeto por parte de outras equipes. Isso considera tanto os meios para acessar como também o próprio fato de informar às equipes sobre a existência dessa fonte de conhecimento útil para outros contextos.

A última fase é a fase 4 - aplicação do conhecimento no receptor. Essa fase é composta por três etapas: (i) absorção e assimilação do conhecimento disponivel por parte de outras equipes de projeto;

Quadro 2. Modelo proposto para as etapas do processo de transferência de conhecimentos.

\begin{tabular}{|c|c|c|c|}
\hline Fase & Etapas & Escopo & Fonte \\
\hline \multirow{2}{*}{$\begin{array}{l}\text { Fase 0: Produção do } \\
\text { conhecimento na fonte } \\
\text { (utilização) }\end{array}$} & $\begin{array}{l}\text { Criação e ampliação do } \\
\text { conhecimento (indivíduos) }\end{array}$ & $\begin{array}{l}0 \text { conhecimento é criado na mente } \\
\text { de cada pessoa durante o trabalho no } \\
\text { projeto. }\end{array}$ & $\begin{array}{l}\text { Alavi e Leidner (2001) e Nonaka } \\
\text { (1994) }\end{array}$ \\
\hline & $\begin{array}{l}\text { Utilização do conhecimento e } \\
\text { aprendizado dentro da equipe }\end{array}$ & $\begin{array}{l}\text { Os integrantes de uma equipe } \\
\text { compartilham seus conhecimentos } \\
\text { e aprendem juntos dentro de um } \\
\text { projeto. }\end{array}$ & $\begin{array}{l}\text { Boer et al. (2001) e Bartezzaghi, } \\
\text { Corso e Verganti (1997) }\end{array}$ \\
\hline \multirow{2}{*}{$\begin{array}{l}\text { Fase } 1: \text { ldentificação } \\
\text { do conhecimento }\end{array}$} & Reconhecimento & $\begin{array}{l}\text { É reconhecida a oportunidade de } \\
\text { aplicar um conhecimento em outros } \\
\text { projetos. A identificação pode ser da } \\
\text { fonte ou do receptor. }\end{array}$ & $\begin{array}{l}\text { Major e Cordey-Hayes (2000) e } \\
\text { Liyanage et al. (2009) }\end{array}$ \\
\hline & Abstração e conceituação & $\begin{array}{l}0 \text { conhecimento é abstraído a um } \\
\text { conceito genérico, aplicável a outros } \\
\text { contextos. }\end{array}$ & $\begin{array}{l}\text { Bartezzaghi, Corso e Verganti } \\
\text { (1997) e Nonaka (1994) }\end{array}$ \\
\hline \multirow{3}{*}{$\begin{array}{l}\text { Fase 2: Processamento } \\
\text { do conhecimento }\end{array}$} & Explicitação e incorporação & $\begin{array}{l}0 \text { conhecimento abstrato é } \\
\text { incorporado em uma primeira versão } \\
\text { de um registro formal. }\end{array}$ & $\begin{array}{l}\text { Markus (2001), Major e } \\
\text { Cordey-Hayes (2000) e Bartezzaghi, } \\
\text { Corso e Verganti (1997) }\end{array}$ \\
\hline & Acondicionamento & $\begin{array}{l}\text { O conhecimento registrado é } \\
\text { formatado, acondicionado, para ficar } \\
\text { claro e compreensível por outras } \\
\text { pessoas. }\end{array}$ & $\begin{array}{l}\text { Markus (2001), Major e } \\
\text { Cordey-Hayes (2000) e } \\
\text { Liyanage et al. (2009) }\end{array}$ \\
\hline & Consolidação & $\begin{array}{l}0 \text { conhecimento acondicionado é } \\
\text { consolidado com a comparação e o } \\
\text { acréscimo, combinação e associação de } \\
\text { outras fontes de conhecimento. }\end{array}$ & $\begin{array}{l}\text { Markus (2001), Major e } \\
\text { Cordey-Hayes (2000) e } \\
\text { Liyanage et al. (2009) }\end{array}$ \\
\hline $\begin{array}{l}\text { Fase } 3: \text { Disseminação } \\
\text { do conhecimento }\end{array}$ & Distribuição/disseminação & $\begin{array}{l}0 \text { conhecimento consolidado é } \\
\text { distribuído ou disseminado para outras } \\
\text { equipes que poderiam utilizá-lo. }\end{array}$ & $\begin{array}{l}\text { Markus (2001) e Bartezzaghi, Corso } \\
\text { e Verganti (1997) }\end{array}$ \\
\hline \multirow{3}{*}{$\begin{array}{l}\text { Fase 4: Aplicação } \\
\text { do conhecimento no } \\
\text { receptor (reutilização) }\end{array}$} & Absorção e assimilação & $\begin{array}{l}\text { Outras equipes de projeto estudam } \\
\text { e aprendem sobre como aplicar o } \\
\text { conhecimento na realidade delas. }\end{array}$ & $\begin{array}{l}\text { Major e Cordey-Hayes (2000) e } \\
\text { Alavi e Leidner (2001) }\end{array}$ \\
\hline & Aplicação & $\begin{array}{l}0 \text { conhecimento é aplicado no novo } \\
\text { projeto. }\end{array}$ & $\begin{array}{l}\text { Major e Cordey-Hayes (2000), Alavi } \\
\text { e Leidner (2001), Liyanage et al. } \\
\text { (2009), Boer et al. (2001) e } \\
\text { Bartezzaghi, Corso e Verganti } \\
\text { (1997) }\end{array}$ \\
\hline & Integração e retenção & $\begin{array}{l}0 \text { conhecimento é integrado às rotinas } \\
\text { e retido permanentemente pela nova } \\
\text { equipe. }\end{array}$ & Szulanski (2000) \\
\hline
\end{tabular}


(ii) aplicação do conhecimento no novo projeto; e (iii) integração do conhecimento às rotinas de trabalho e retenção do conhecimento pelas pessoas da equipe. A capacidade absortiva é essencial para as equipes receptoras do conhecimento. Como resultado de uma boa capacidade absortiva do conhecimento transferido, tem-se a incorporação do conhecimento a novas soluções para o projeto.

É importante ressaltar que o modelo apresentado propõe todas as etapas para uma TC formal e estruturada dentro da organização. Esse tipo de análise é própria da abordagem de engenharia, que busca propor soluções para a TC, geralmente baseadas em métodos estruturados e sistemas de informações. Além disso, essas formas de TC crescem em importância, considerando a tendência de internacionalização das atividades de DP. Em muitas empresas, as equipes começam a ser organizadas de uma maneira diferente da forma tradicional de equipes colocalizadas, sendo o trabalho estruturado através de equipes geograficamente distanciadas que trabalham em conjunto de maneira virtual (SONG et al., 2007; MONTOYA et al., 2009). Nessa forma de trabalho, a TC estruturada, em formatos explícitos, é essencial para que as equipes possam acessar as fontes de conhecimento de projetos que se desenvolvem em outros lugares.

No caso dos conhecimentos serem transferidos através da interação face a face das pessoas, algumas das etapas propostas nesse modelo não ocorreriam de uma maneira tão clara e evidente. Isso acontece especialmente na fase 2 - processamento, pois nesse caso não há registros formais, ocorrendo o processamento na mente das equipes que estão interagindo. Nesse caso, ainda irão ocorrer explicitação, acondicionamento e consolidação do conhecimento, como proposto no presente modelo, mas de uma maneira menos definida a separação entre cada uma das etapas. Além disso, a fase 3 - disseminação - acontecerá simultaneamente à fase 2 , pois nesse caso trata-se de interações entre indivíduos que estarão processando o conhecimento enquanto compartilham e discutem a respeito de soluções para os projetos.

\section{Conclusões}

0 presente trabalho apresentou uma análise dos diferentes modelos de TC existentes, possibilitando avançar na proposição de um modelo consolidado para o processo de TC entre os projetos de DP. Os resultados obtidos permitem melhor compreensão de tal processo, assim como das suas fundamentações teóricas de acordo com as diferentes abordagens e linhas de pesquisas existentes.
0 modelo proposto é composto de cinco fases: (i) fase 0 - produção do conhecimento na fonte, que contempla as etapas de criação e ampliação do conhecimento nos indivíduos e utilização do conhecimento e aprendizado dentro da equipe; (ii) fase 1 - identificação do conhecimento, contempla as etapas de reconhecimento e de abstração e conceituação do conhecimento; (iii) fase 2 - processamento do conhecimento, contempla as etapas de explicitação e incorporação do conhecimento, acondicionamento e consolidação do conhecimento; (iv) fase 3 - disseminação do conhecimento, considera uma única etapa de distribuição ou disseminação do conhecimento; e (v) fase 4 - aplicação do conhecimento no receptor, contempla as etapas de absorção e assimilação, aplicação, integração e retenção do conhecimento no novo projeto.

Considerando os resultados deste artigo, trabalhos futuros poderiam abordar dois aspectos-chave. 0 primeiro aspecto trata do enfoque utilizado neste trabalho. 0 modelo proposto seguiu o enfoque dos modelos de engenharia, onde a TC é geralmente formal e está focada em soluções práticas, utilizando sistemas e métodos estruturados para disseminar os conhecimentos. Por conseguinte, mesmo que neste trabalho tenha-se discutido também o enfoque emergente, que considera a TC por meio da socialização e interação entre as equipes de diferentes projetos, esse é um tema que exige maior aprofundamento. Uma contribuição útil para o estado da arte seria a proposição de um modelo baseado no enfoque emergente.

0 segundo aspecto que demanda estudos futuros está associado com a análise dos fatores de TC. Existem muitos trabalhos que estudam a influência de diferentes fatores organizacionais sobre a TC, mas considerando esta como um evento único. Futuros trabalhos poderiam estudar a influência de tais fatores sobre a TC, desdobrando esta em etapas específicas de um processo e considerando que os fatores podem ter diferentes influências sobre cada uma dessas etapas.

\section{Agradecimentos}

Este artigo é resultado do projeto "Programa Pesquisador Gaúcho - FAPERGS PqG" № 06/2010, processo 1.008.515. Os autores também agradecem ao CNPq pelo apoio financeiro recebido através de bolsas de pesquisas.

\section{Referências}

AKGÜN, A. E.; LYNN, G. S.; YILMAZ, C. Learning process in new product development teams and effects on product success: A socio-cognitive perspective. Industrial Marketing Management, v. 35, n. 2, p. 210-224, 2006. 
ALAVI, M.; LEIDNER, D. Knowledge management and knowledge management systems: conceptual foundations and research issues. Management Information Systems Quarterly, v. 25, n. 1, p. 107-136, 2001.

ANTONI, M. et al. Inter-project improvement in product development. International Journal of Quality \& Reliability Management, v. 22, n. 9, p. 876-893, 2005. http://dx.doi.org/110.1108/02656710510625194

ARGOTE, L.; INGRAM, P. Knowledge transfer: A basis for competitive advantage in firms. Organizational Behavior and Human Decision Processes, v. 82, n. 1, p. 150-169, 2000. http://dx.doi.org/10.1006/ obhd.2000.2893

BARDIN, L. L'Analyse de Contenu. Paris: Presses Universitaires de France, 1977.

BARTEZZAGHI, E.; CORSO, M.; VERGANTI, R. Continuous improvement and inter-project learning in new product development. International Journal of Technology Management, v. 14, n. 1, p. 116-138, 1997. http:// dx.doi.org/10.1504/IJTM.1997.001704

BOER, H. et al. Knowledge and continuous innovation The CIMA methodology. International Journal of Operations \& Production Management, v. 21, n. 4, p. 490-503, 2001.

COHEN, M. D.; BACDAYAN, P. Organizational routines are stored as procedural memory: evidence from a laboratory study. Organization Science, v. 5, n. 4, p. 554-568, 1994.

COHEN, W. M.; LEVINTAL, A. Absorptive Capacity: A new perspective on learning and innovation. Administrative Science Quarterly, v. 35, p. 128-152, 1990.

CUMMINGS, J. L.; TENG, B-S. Transferring R \& D knowledge: the key factors affecting knowledge transfer success. Journal of Engineering and Technology Management, v. 20 , p. 39-68, 2003. http://dx.doi.org/10.1016/S09234748(03)00004-3

CUMMINGS, J.N. Work Groups, Structural Diversity, and Knowledge Sharing in a Global Organization. Management Science, v. 50, p 352-64, 2004.

DAVENPORT, T. H., PRUSAK, L. Working Knowledge. Boston: Harvard Business Scholl Press, 1998.

DU, R., Al, S., REN, Y. Relationship Between Knowledge Sharing and Performance: A Survey in $\mathrm{Xi}_{\mathrm{i}}$ 'an, China. Expert Systems with Applications v. 32, p. 38-46, 2007.

GUPTA, A. K.; GOVINDARAJAN, V. Knowledge Flows Within Multinational Corporations. Strategic Management Journal, v. 21, n. 4, p. 473-96, 2000. http://dx.doi. org/10.1002/(SICl) 1097-0266(200004)21:4<473::AIDSMJ84>3.0.CO;2-1

HORTON, A.M. A Simple Guide to Successful Foresight. Foresight, v. 1, n. 1, p. 5-9, 1999.

HSU, 1.-C. Knowledge sharing practices as a facilitating factor for improving organizational performance through human capital: A preliminary test. Expert Systems with Applications, v. 35, n. 3, p. 1316-1326, 2008. http:// dx.doi.org/10.1016/j.eswa.2007.08.012

KOGUT, B.; ZANDER, U. Knowledge of the firm, combinative capabilities and the replication of technology. Organization Science, v. 3, n. 3, p. 383-397, 1992.

KONERS, U.; GOFFIN, K. Learning from Postproject Reviews: A Cross-Case Analysis. Journal of Product Innovation Management, v. 24, n. 3, p. 242-258, 2007a.

KONERS, U.; GOFFIN, K. Managers' perceptions of learning in new product development. International Journal of Operations \& Production Management, v. 27, n. 1, p. 49-68, 2007b.

LEWIS, K.; LANGE, D.; GILLIS, L. Transactive memory systems, learning, and learning transfer. Organization Science, v. 16, n. 6, p. 581-598, 2005. http://dx.doi.org/10.1287/ orsc. 1050.0143

LIAO, S.-H.; HU, T.-H. Knowledge transfer and competitive advantage on environmental uncertainty: An empirical study of the Taiwan semiconductor industry. Technovation, v. 27, n. 6-7, p. 402-411, 2007. http://dx.doi.org/10.1016/j. technovation.2007.02.005

LIU, D-R., KE, C-K. Knowledge Support for Problem-solving in a Production Process: A Hybrid of Knowledge Discovery and Case-based Reasoning. Expert Systems with Applications, v 33, no. 1, p 147-161, 2007.

LIYANAGE, C. et al. Knowledge communication and translation - a knowledge transfer model. Journal of Knowledge Management, v. 13, n. 3, p. 118-131, 2009. http://dx.doi.org/10.1108/13673270910962914

LYNN, G. S.; REILLY, R. R.; AKGÜN, A. E. Knowledge Management in New Product Teams: Practices and Outcomes. IEEE Transactions on Engineering Management, v. 47, n. 2, p. 221-231, 2000.

MAJOR, E. J.; CORDEY-HAYES, M. Engaging the business support network to give SMEs the benefit of foresight. Technovation, v. 20, n. 11, p. 589-602, 2000. http:// dx.doi.org/10.1016/S0166-4972(00)00006-7

MARKUS, M. L. Toward a Theory of Knowledge Reuse : Types of Knowledge Reuse Situations and Factors in Reuse Success. Journal of Management Information Systems, v. 18 , n. 1, p. 57-93, 2001.

MARSH, S. J.; STOCK, G. N. Building Dynamic Capabilities in New Product Development through Intertemporal Integration. Journal of Product Innovation Management, v. 20, p. 136-148, 2003. http://dx.doi.org/10.1111/15405885.2002006

MONTOYA, M.; MASSEY, A.; HUNG, Y., CRISP, C. Can You Hear Me Now? Communication in Virtual Product Development Teams. Journal of Product Innovation Management, p 139-155, 2009.

NILSSON-WITELL, L.; ANTONI, M.; DAHLGAARD, J. J. Continuous improvement in product development Improvement programs and quality principles. International Journal of Quality \& Reliability Management, v. 22, n. 8, p. 753-768, 2005. http:// dx.doi.org/10.1108/02656710510617210

NOBEOKA, K.; CUSUMANO, M. A. Multiproject strategy and sales growth: the benefits of rapid design transfer in new product development. Strategic Management Journal, v. 18, n. 3, p. 169-86, 1997.

NOBEOKA, K.; CUSUMANO, M. A. Multiproject Strategy Design Transfer , and Project Performance: A Survey of Automobile Development Projects in the US and Japan. IEEE Transactions on Engineering Management, v. 42, n. 4, p. 397-409, 1995.

NONAKA, 1. A dynamic theory of organizational knowledge creation. Organization Science, v. 5, n. 1, p. 14-37, 1994.

PRENCIPE, A.; TELL, F. Inter-project learning: processes and outcomes of knowledge codification in project-based firms. Research Policy, v. 30, n. 9, p. 1373-1394, 2001. http://dx.doi.org/10.1016/S0048-7333(01)00157-3

RAMESH, B.; TIWANA, A. Supporting Collaborative Process Knowledge Management in New Product 
Development Teams. Decision Support Systems, v. 27, p. 213-235, 1999.

RAUNIAR, R. et al. Shared knowledge and product design glitches in integrated product development. International Journal of Production Economics, v. 114 , p. 723-736, 2008. http://dx.doi.org/10.1016/j. ijpe.2008.03.005

SCHLEGELMILCH, B. B.; CHINI, T. C. Knowledge transfer between marketing functions in multinational companies: A conceptual model. International Business Review, v.12, no. 2, p. 215-232, 2003. http://dx.doi. org/10.1016/S0969-5931(02)00097-5

SMALLENBURG, K.; HALMAN, J.; VAN MAL, H. H. Towards re-use of knowledge in the concept stage of development. International Journal of Technology Management, v. 11, n. 3-4, p. 343-353, 1996

SONG, X. et al. The Effect of IT and Co-location on Knowledge Dissemination. Journal of Product Innovation Management, v. 24, p 52-68, 2007. http://dx.doi. org/10.1111/j.1540-5885.2006.00232.x

SZULANSKI, G. The Process of Knowledge Transfer: A Diachronic Analysis of Stickiness. Organizational Behavior and Human Decision Processes, v. 82, n. 1, p. 9-27, 2000. http://dx.doi. org/10.1006/obhd.2000.2884
TROTT, P.; CORDEY-HAYES, M.; SEATON, R. Inward technology transfer as an interactive process. Technovation, v. 15, n. 1, p. 25-43, 1995.

TSENG, S.-M. The effects of information technology on knowledge management systems. Expert Systems With Applications, v. 35, n. 1-2, p. 150-160, 2008. http:// dx.doi.org/10.1016/j.eswa.2007.06.011

VAN DEN HOOFF, B.; Huysman, M. Managing knowledge sharing: Emergent and engineering approaches. Information \& Management, v. 46, n. 1, p. 1-8, 2009. http://dx.doi.org/10.1016/j.im.2008.09.002

VAN WIJK, R.; JANSEN, J. J. P.; LYLES, M. A. Inter- and intra-organizational knowledge transfer: a meta-analytic review and assessment of its antecedents and consequences'. Journal of Management Studies, v. 45, n. 4, p. 815-38, 2008. http://dx.doi.org/10.1111/ j.1467-6486.2008.00771.x

ZANDER, U.; KOGUT, B. Knowledge and the speed of the transfer and imitation of organizational capabilities: an emprirical test. Organization Science, v. 6, n. 1, p. 76-92, 1995.

ZOLLO, M.; WINTER, S. G. Deliberate learning and the evolution of dynamic capabilities. Organization Science, v. 13, n. 3, p. 339-351, 2002. http://dx.doi.org/10.1287/ orsc. 13.3.339.2780

\title{
Towards a consolidated model of knowledge transfer between product development projects
}

\begin{abstract}
Knowledge Transfer (KT) between New Product Development (NPD) projects is a process that comprises several stages. In the literature, many works have proposed KT stages, but there is heterogeneity in the nomenclature used in these works and, also, in the organization of the proposed KT stages. In addition, many research fields have studied the KT process, resulting on different interpretation or approaches of this process. Therefore, this study presents a comparison of nine KT models proposed by authors of different research fields that were organized in two main approaches: the emergent approach (which considers the team dynamic and team integration) and the engineering approach (which considers the organization and management of knowledge). The comparison is based on a content analysis of the proposed models. As a result, it is proposed a new model for KT between NPD projects. This model presents a reorganization of the ideas discussed in the literature and an integration of the different existing models, obtaining a more comprehensive and consistent KT model. This study also highlights the contributions and differences between the main $\mathrm{KT}$ research fields.
\end{abstract}

Keywords

Knowledge transfer. New product development. Project teams. Model. 